\title{
VOGT-KOYANAGI-HARADA SYNDROME: A CASE REPORT
}

Ithaan Barboza da Silva (Hospital Geral de Fortaleza, Fortaleza, CE, Brasil), Jokasta Nunes Lobo (Hospital Geral de Fortaleza, Fortaleza, CE, Brasil), Matheus Andrighetti Rossi (Hospital Geral de Fortaleza, Fortaleza, CE, Brasil), Lia Poti Gomes Cordeiro (UniChristus, Fortaleza, CE, Brasil), Kirla Wagner Poti Gomes (UNIFOR, Fortaleza, CE, Brasil)

\section{BACKGROUND}

The Vogt-Koyanagi-Harada (VKH) syndrome is a disease that affects

organs which contain melanocytes, including meninges, skin, mucous membranes, inner ear and eyes, whose outcomes include serious functional damages in affected patients. The diagnosis is reached through clinical tests, based on criteria laid down in 1999, by the American Society of Uveitis, which include the multi-systemic character of the syndrome. Due to its autoimmune nature, the treatment comprises immunosuppressive therapy, including TNF-a inhibitors.

\section{CASE REPORT}

A female, 18-year-old patient presented onset of red and painful eyes. After a week, she reported visual and auditory loss. Seven months later, she evolved with poliosis in eyelashes, eyebrows and hair, besides achromic lesions in trunk, with diagnosis of vitiligo. She underwent oral $(1 \mathrm{mg} / \mathrm{kg} / \mathrm{day})$ and ocular corticosteroids, with improvement of the visual acuity, in spite of identification of panuveitis. Immunoglobulin and azathioprine were added, but the symptoms returned whenever the corticosteroid was reduced. Because of the treatment inefficacy, the patient was referred to a tertiary center, where adalimumab, a TNF-a blocker, was initiated.

\section{CONCLUSION}

VKH is a rare condition whose early detection prevents visual and auditory sequels. The suggested treatment after inadequate response to corticosteroid and azathioprine or others immunosuppressives medications is TNF-a inhibitors, and the one with more scientific evidences is adalimumab. 